\title{
Design of Z-Shape Microstrip Antenna with I- Slot for Wi-Max/Satellite Application
}

\author{
Swarnaprava Sahoo and Mihir Narayan Mohanty \\ Department of Electronics and Communication Engineering, ITER, Siksha 'O’ Anusandhan University, Bhubaneswar, Odisha
}

\begin{abstract}
In current scenario, the demand in wireless communication increases rapidly. As the growth of the technology increases, in the same way the antenna research requires in high rate. Mostly the patch antenna creates the focus of the researchers. Multiband but single feed microstrip antenna has been proposed in this work. It is of Z-shape with I-slot antenna that operates at $3.5 \mathrm{GHz}$ and 4.3 $\mathrm{GHz}$ which can be used for Wi-Max/S-band \&C-band satellite applications. As the radiating edges of the antenna are cut by the slot, the multiple frequency response is generated. In this Z-shape antenna I-slot has been created on the radiating edge for which dual frequency response is achieved. The return losses at $3.5 \mathrm{GHz}$ and $4.3 \mathrm{GHz}$ are $-18.88 \mathrm{~dB}$ and $-16.42 \mathrm{~dB}$ respectively. Its bandwidth is of $140.7 \mathrm{MHz}$ (lower band) to $131.5 \mathrm{MHz}$ (upper band). A pair of slits has been inserted in the radiating edge to form Z-shape patch antenna and improved the performance. The proposed antenna designed in this paper exhibits enhanced bandwidth with multi resonant frequency. In this work, a geometric Z-shape is developed from a rectangular patch of width $(\mathrm{W}=38.04 \mathrm{~mm})$ and length $(\mathrm{L}$ $=29.44 \mathrm{~mm})$. The antenna is designed using FR4-epoxy substrate with a dielectric constant $\left(\boldsymbol{\varepsilon}_{\boldsymbol{r}}\right)$ of 4.4 and a thickness of $1.6 \mathrm{~mm}$ respectively. The result of proposed antenna is obtained in terms of return loss and bandwidth. Its radiation patterns are also studied. The simulated result shows that the Z-shape patch antenna with I-slot has the highest bandwidth in comparison with patch and Z-shape.
\end{abstract}

Key words: Microstrip antenna, Wi-Max, multi band antenna, dual band antenna, broadband antenna.

\section{Introduction}

Microstrip antenna is more attracted because of its size, weight, profile is in small order as well as easier to fabricate. Microstrip antennas have attracted more interest in satellite and wireless mobile communication [1,2]. Broadband applications have been achieved by changing the shape and creating the slots in the design of the antenna. Requirements of the multi frequency band in wireless communication enrich its research. If a single small device can work in various frequency bands it helps to reduce the size, weight and circuitry [3, 4]. This boosts the researchers to work in this area. Similarly the feed of the antenna is an important aspect. In many ways it can be fed to the antenna. Also for best performance the position of the feed can be changed and verified by the researchers [5]. It is broadly categorized as contact

Corresponding author: Swarnaprava Sahoo, M. Tech, research fields: antenna design and signal processing. and non-contact type of feeds. Microstrip patch antennas are increasingly finding their applications in a broad range of microwave systems from radars, telemetry, navigation, biomedical systems, mobile and satellite communications, GPS (global positioning system) for remote sensing and etc. In case of contact based power is fed directly to the radiating patch, whereas in the non-contact case electromagnetic field requires coupling to transfer the RF power. Out of four popular contact based feed, we have considered the microstrip line feed, since non-contact based feed is somewhat complex.

In this paper, design of single feed dual band Z-shape microstrip antenna with I-slot operated at 3.5 $\mathrm{GHz}$ and $4.3 \mathrm{GHz}$ for Wi-Max/S-band\&C-band satellite application is presented. It has been verified that by cutting the slots into radiating edges of microstrip patch antenna, a dual frequency response is achieved. The performance is improved by inserting a pair of slits in an appropriate radiating edge to form 
Z-shape patch antenna. The proposed antenna designed exhibits enhanced bandwidth with multi resonant frequency. In this work, a geometric Z-shape is developed from a rectangular patch. The antenna is designed using FR4-epoxy substrate with a dielectric constant $\left(\varepsilon_{r}\right)$ of 4.4 and a thickness of $1.6 \mathrm{~mm}$ respectively. The simulated result shows that the Z-shape patch antenna with I-slot has the highest bandwidth in comparison with patch and Z-shape.

The paper is organized as follows: Section 1 introduces the work; Section 2 explains the antenna design; the results are exhibited in section 3 and finally, section 4 concludes the work.

\section{Antenna Design}

\subsection{Design Methodology}

Microstrip patch antennas consist of a very thin metallic strip (patch) placed on a ground plane where the thickness of the metallic strip is restricted by $\mathrm{t}<<$ $\lambda_{0}$ and the height is restricted by $0.0003 \lambda_{0} \leq \mathrm{h} \leq \lambda_{0}$ where $\lambda_{0}$ is the free space wavelength. The microstrip patch is designed so that its radiation pattern maximum is normal to the patch. For a rectangular patch, the length $\mathrm{L}$ of the element is usually $\frac{\lambda_{0}}{3}<L<\frac{\lambda_{0}}{2}$. The dimension has major impact on operating frequency [6-7].

\subsection{Antenna Design Procedure}

The bandwidth of an antenna is mainly determined by the thickness, the nature of the dielectric substrate and the geometry of the antenna. To expose the bandwidth matter in simple planar structures and to give a benchmark in terms of space and bandwidth, a rectangular patch has first been sized. The dimensions of the antenna can be deduced from analytical expressions [2, 3]. Increasing the width of this antenna is one of factors controlling its bandwidth. Nevertheless, it is very difficult to obtain a satisfactory result with a simple shape microstrip patch antenna. That is why we propose Z-shape geometry in order to widen the bandwidth of the antenna while retaining reasonable dimensions. This geometry changes the distribution of surface current density generating multiple resonances [8-11].

The goal of designing a microstrip antenna at 3.5 $\mathrm{GHz}$ and $4.3 \mathrm{GHz}$ was to improve bandwidth and directivity for the Wi-Max/S- band \& C-band Satellite application. The width of the rectangular patch antenna is usually chosen to be larger than the length of the patch to get higher bandwidth. To design patch antenna lower dielectric constant is used because in case of lower dielectric constant of the substrate, surface wave losses are more severe and dielectric and conductor losses are less severe. Table 1 shows the specifications for the proposed microstrip patch antenna.

\subsection{Design of Z-Shaped Microstrip Patch Antenna}

The most important design features of the patch are its width (W), length (L), width of transmission line and the length of the feeding line. The patch is fed by a $50 \Omega$ inset feed. The geometry and configuration of Z-shaped microstrip patch antenna is shown in Fig. 1 and Fig. 2.

Table 2 shows the parameters for the proposed Z-shape microstrip patch antenna.

\section{Experimental Results}

The proposed antenna is to be used for the Wi-Max/Satellite application. The entire simulation is

Table 1 Design specification of patch antenna.

\begin{tabular}{ll}
\hline Parameter & Value \\
\hline Substrate & FR4-epoxy \\
Center frequency $\left(\mathrm{f}_{\mathrm{r}}\right)$ & $2.32 \mathrm{GHz}, 3.62 \mathrm{GHz}$ \\
Height of substrate $(\mathrm{h})$ & $1.6 \mathrm{~mm}$ \\
Loss tangent & 0.02 \\
Dielectric constant $\left(\varepsilon_{r}\right)$ & 4.4 \\
Width of patch $(\mathrm{W})$ & $38.04 \mathrm{~mm}$ \\
Length of patch $(\mathrm{L})$ & $29.44 \mathrm{~mm}$ \\
Feed width $\left(\mathrm{w}_{0}\right)$ & $1.8 \mathrm{~mm}$ \\
$\mathrm{y}_{0}$ & $5 \mathrm{~mm}$ \\
$\mathrm{x}_{0}$ & $0.6 \mathrm{~mm}$ \\
\hline
\end{tabular}




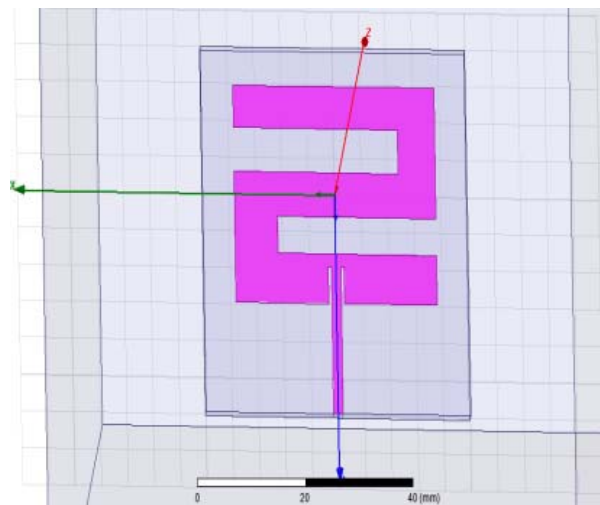

Fig. 1 Z-shape microstrip patch antenna.

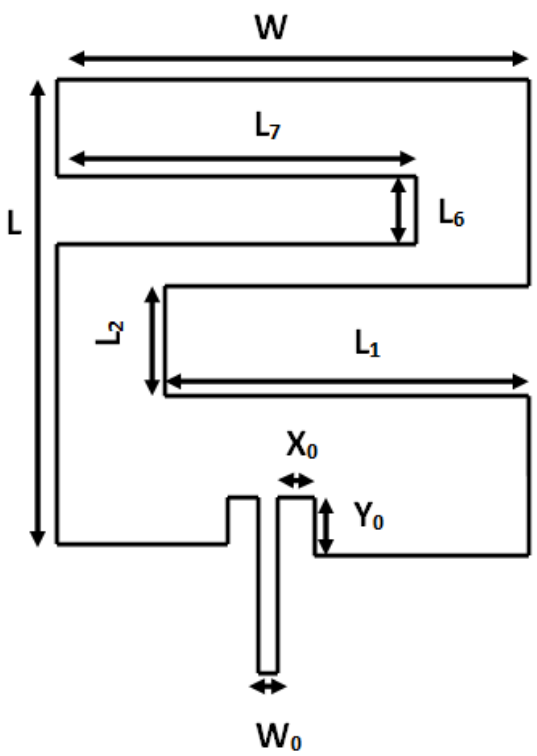

Fig. 2 Patch configuration of Z-shape microstrip patch antenna.

Table 2 Parameters of Z-shape patch antenna.

\begin{tabular}{ll}
\hline Parameter & Value \\
\hline $\mathrm{L}_{1}$ & $30 \mathrm{~mm}$ \\
$\mathrm{~L}_{2}$ & $5 \mathrm{~mm}$ \\
$\mathrm{~L}_{6}$ & $6 \mathrm{~mm}$ \\
$\mathrm{~L}_{7}$ & $32 \mathrm{~mm}$ \\
\hline
\end{tabular}

simulated using Ansoft HFSS-13. The antenna is to operate in the frequency range from 92.7 $\mathrm{MHz}$ (lower band) to $130.7 \mathrm{MHz}$ (upper band). The dielectric material selected is FR4-epoxy which has a dielectric constant of 4.4. A thick dielectric substrate having a low dielectric constant is selected for better efficiency, larger bandwidth and better radiation. The objective is to get an improve bandwidth from the conventional microstrip patch. The bandwidth is obtained where return loss is less than $-10 \mathrm{~dB}$ which is an acceptable level to describe the loss of the power which reflects back from the antenna without being radiated. The antenna is designed for the operating frequency of 3.35 GHz and 4.25 GHz. Fig. 3 shows the simulated result of return loss. It is shown useful return loss peaks at $3.35 \mathrm{GHz}$ is $-17.82 \mathrm{~dB}$ and at $4.25 \mathrm{GHz}$ is $-17.49 \mathrm{~dB}$.

Bandwidth $\%$ of rectangular microstrip patch antenna: $3.75 \%$ at $2.32 \mathrm{GHz}$ and $2.22 \%$ at $3.62 \mathrm{GHz}$.

Bandwidth \% of Z-shape microstrip patch antenna: $2.76 \%$ at $3.35 \mathrm{GHz}$ and $3.07 \%$ at $4.25 \mathrm{GHz}$.

The antenna resonates at two bands of frequency at $3.35 \mathrm{GHz}$ and $4.25 \mathrm{GHz}$. Fig. 3 shows two resonant frequencies. These frequencies are related to the dimension $\left(\mathrm{L}_{1}, \mathrm{~L}_{2}\right.$ and $\left.\mathrm{L}_{6}, \mathrm{~L}_{7}\right)$. These dimensions are linked by the fact that the single excitation point must have matched impedance $(50 \Omega)$ with the two resonant frequencies. Bringing closer these two resonant frequency is possible when we inset an I-shape slot in the middle of the Z-shape as seen in Fig. 4. The configuration of Z-shaped microstrip patch antenna with I-slot is shown in Fig. 5.

Table 3 shows the specifications for the proposed Z-shape microstrip patch antenna with I-slot.

Fig. 6 shows the simulated result of return loss.

The antenna is to operate in the frequency range from 140.7 MHz (lower band) to $131.5 \mathrm{MHz}$ (upper band). The antenna resonates at two bands of frequency at $3.5 \mathrm{GHz}$ and $4.3 \mathrm{GHz}$. We notice that the bandwidth is wider than the bandwidth of a reference antenna represented by a rectangular patch with a center frequency of $2.32 \mathrm{GHz}, 3.62 \mathrm{GHz}$.

The radiation pattern obtained at both frequency by simulation is given in Figs. 7-10.

The two resonances inside the bandwidth are related to the different lengths of the $\mathrm{Z}$-shape $\left(\mathrm{L}_{1}, \mathrm{~L}_{2}\right.$ and $\mathrm{L}_{6}, \mathrm{~L}_{7}$ ). Indeed, they should have been separate but they have close due to the inclusion of I-shape slot. We then obtain a wider bandwidth around 140.7 MHz. The proposed antenna has the advantage to achieve wide 


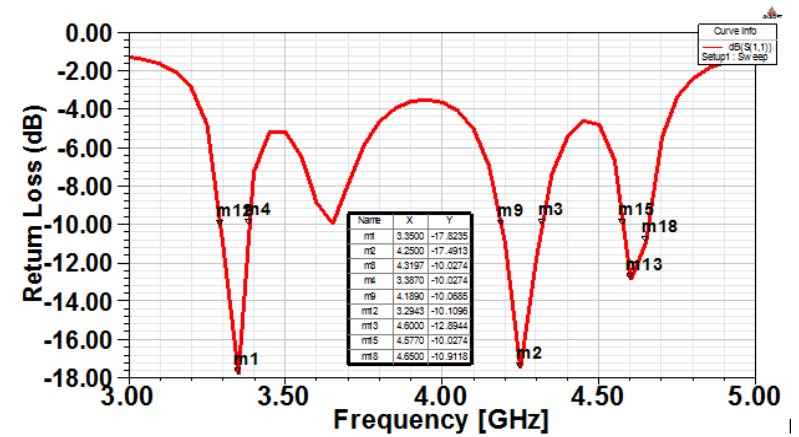

Fig. 3 Return loss plot of Z-shape patch antenna.

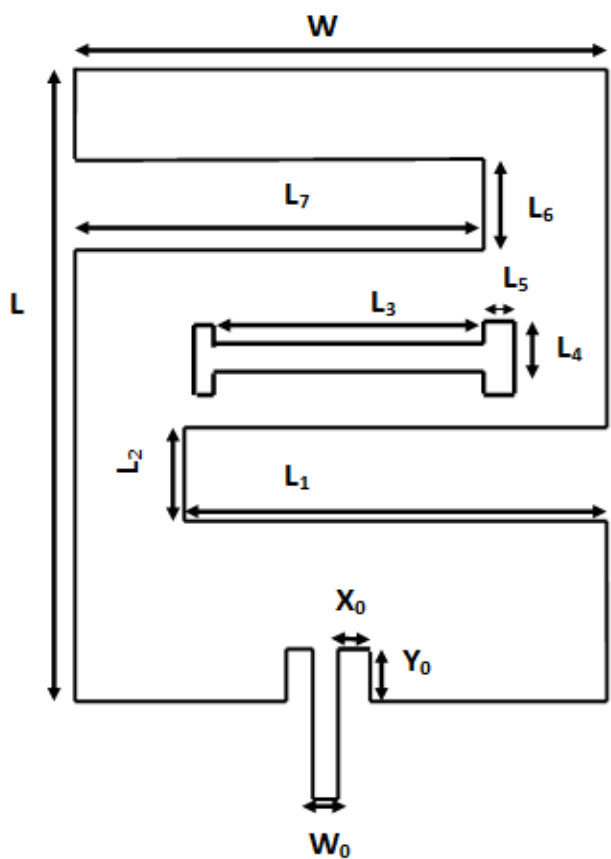

Fig. 5 Patch configuration of Z-shape microstrip patch antenna with I-slot.

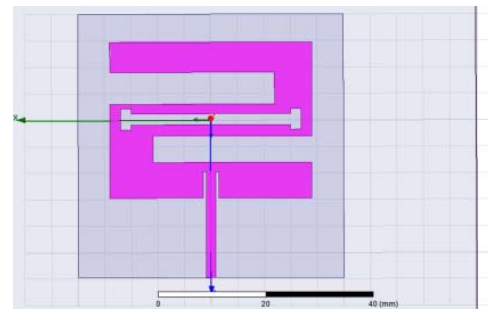

Fig. 4 Z-shape microstrip patch antenna with I-slot.

Table 3 Design specification of Z-shape patch antenna with I-Slot.

\begin{tabular}{ll}
\hline Parameter & Value \\
\hline $\mathrm{L}_{3}$ & $30 \mathrm{~mm}$ \\
$\mathrm{~L}_{4}$ & $4 \mathrm{~mm}$ \\
$\mathrm{~L}_{5}$ & $2 \mathrm{~mm}$ \\
\hline
\end{tabular}

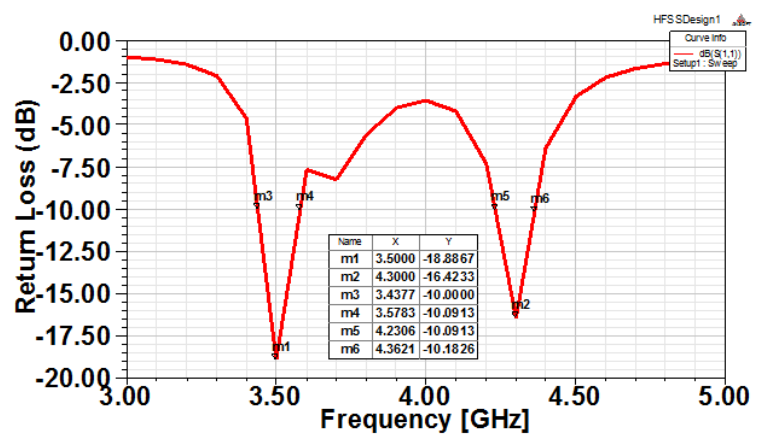

Fig. 6 Return loss plot of Z-shape patch antenna with I-slot.

Table 4 Bandwidth (\%) efficiency in terms of resonates frequency.

\begin{tabular}{ll}
\hline Antenna & $\begin{array}{l}\text { Bandwidth (\%) efficiency respect } \\
\text { to the resonates frequency }\end{array}$ \\
\hline $\begin{array}{l}\text { Rectangular microstrip } \\
\text { patch antenna }\end{array}$ & $2.98 \%$ \\
$\begin{array}{l}\text { Z-shape patch antenna } \\
\text { Z-shape with I slot patch } \\
\text { antenna }\end{array}$ & $3.91 \%$ \\
\hline
\end{tabular}

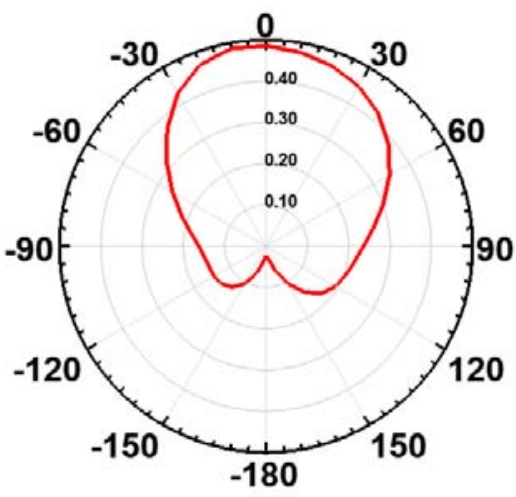

Fig. 7 Radiation pattern (gain) at $3.5 \mathrm{GHz}$.

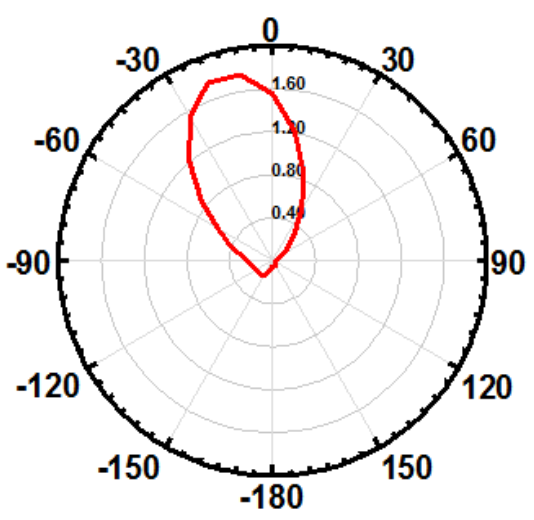

Fig. 8 Radiation pattern (gain) at $4.3 \mathrm{GHz}$. 


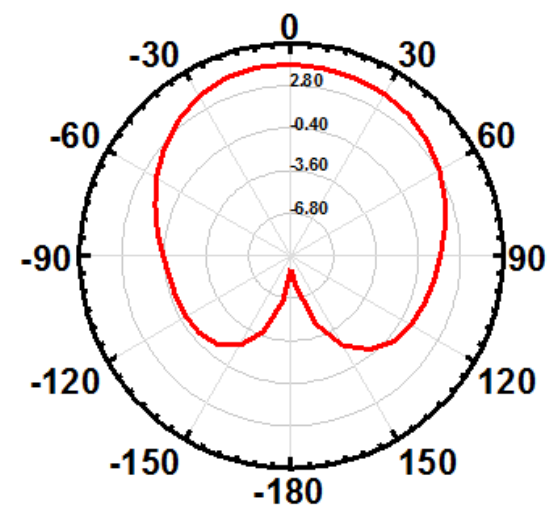

Fig. 9 Radiation pattern (directivity) at $3.5 \mathrm{GHz}$.

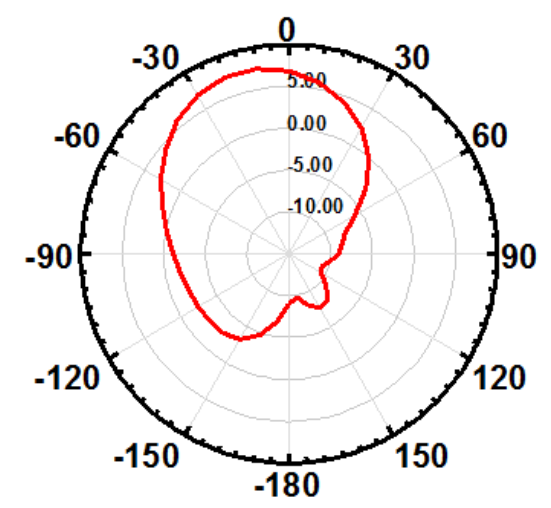

Fig. 10 Radiation pattern (directivity) at $4.3 \mathrm{GHz}$.

bandwidth without enlarging the size of the patch by simply adding an I-slot inside the Z-shape antenna.

\section{Conclusion}

The Z-shape patch antenna is proposed for multi frequency operations. The antenna shall be suitable for Wi-Max/ S- band\&C-band satellite application. The Z-shape microstrip patch antenna at $3.35 \mathrm{GHz}$ and 4.25 GHz for WLAN/S- band\&C-band satellite application was designed. The proposed Z-shape patch antenna with I-slot performs better than the conventional patch antenna which is approximately $3.53 \%$ of bandwidth efficiency in terms of resonant frequency.

\section{References}

[1] Wong, K. L. 2003. Compact and Broadband Microstrip Antennas. John Wiley \& Sons.

[2] James, R. 1989. Handbook of Microstrip Antenna. London: Peter Peregrinus Ltd.

[3] Garg, R., Bharta, P., and Ittipiboon, A. 2001. Microstrip Antenna Design Handbook. New York: Artech House.

[4] Maci, S., and Gentilli, G. B. 1997. "Dual-Frequency Patch Antennas." IEEE Trans Antennas Propagation Mag 39: 13-20.

[5] Mahapatra, S., and Mohanty, M. N. 2014. "Simulation and Feed Analysis of Microstrip Antenna for UWB Communication." Presented at the IEEE Conf. ICCPCT, Noorul Islam University, Kanyakumari, TN, India.

[6] Milligan, T. A. 2007. Modern Antenna Design. 2nd ed., IEEE Press, John Wiley \& Sons inc..

[7] Mailoux, R. J., Mellyenna, J. F., and Kemweis, N. P. 1981. "Microstrip Array Technology." IEEE Trans. Antenna Propagation Magazine 29: 25-7.

[8] Kumari, R., and Kumar, M. 2013. "Diamond Shaped Microstrip Patch Antenna for Dual Band Operation." Presented at the IEEE Conference IMPACT.

[9] Yang, S. L. S., Kishk, A. A., and Lee, K. F. 2008. "Frequency Reconfigurable U-Slot Microstrip Patch Antenna." Antennas \&Wireless Propagation Letters 7: 127-9.

[10] Singh, S. K., Consul, P., and Sharma, K. K. 2015. "Dual Band Gap Coupled Microstrip Antenna Using L-Slot DGS for Wireless Applications." Presented at the IEEE Conference ICCCA.

[11] Deshmukh, A. A., Padita, V., Colaco, R., and Doshi, R. 2014. "Dual Band Dual Polarized Modified Circular Microstrip Antenna." Presented at the IEEE Conference ISCITA. 